\title{
Control of the Porosity in Manganese Trimer-Based Metal Organic Frameworks by Linker Functionalization
}

\author{
Mohammad Rasel Mian, ${ }^{1}$ Unjila Afrin, ${ }^{1}$ Majed S. Fataftah, ${ }^{1}$ Karam B. Idrees, ${ }^{1}$ Timur \\ Islamoglu, ${ }^{1}$ Danna Freedman, ${ }^{1}$ Omar K. Farha $* 1,2$ \\ ${ }^{1}$ Department of Chemistry and International Institute of Nanotechnology, Northwestern University, \\ 2145 Sheridan Road, Evanston, IL 60208, United States. \\ ${ }^{2}$ Department of Chemical \& Biological Engineering, Northwestern University, 2145 Sheridan Road, \\ Evanston, IL 60208, United States.
}

Table of Contents

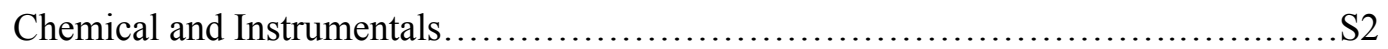

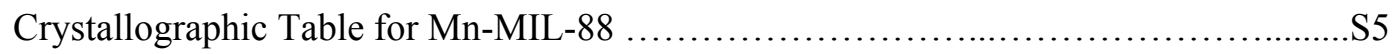

Thermogravimetric analysis of Mn-MIL-88 and Mn-MIL-88-Me ${ }_{4} \ldots \ldots \ldots \ldots \ldots \ldots \ldots . . . \ldots 6$

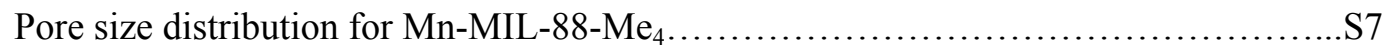

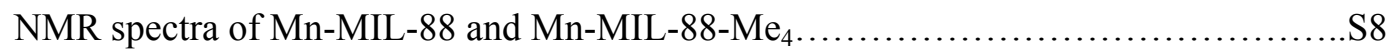

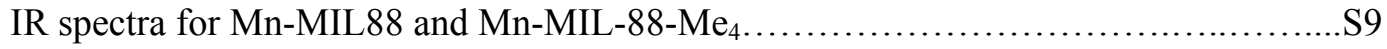

XPS for Mn-MIL-88, Mn-MIL-88-Me 4 , Mn(II) salt and Mn(III) salt........................S10

$100 \mathrm{~K}$ magnetization data for Mn-MIL-88 and Mn-MIL-88-Me ${ }_{4} \ldots \ldots \ldots \ldots \ldots \ldots . . . . . . . . . .11$

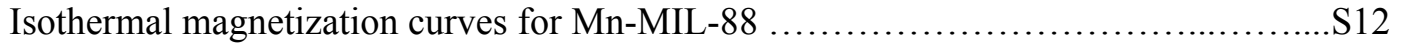

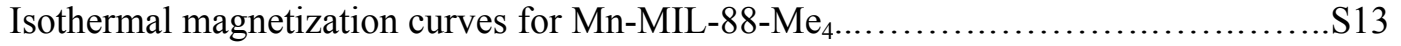

Variable field dc magnetic susceptibility for Mn-MIL-8 $\ldots \ldots \ldots \ldots \ldots \ldots \ldots \ldots \ldots . . . .514$

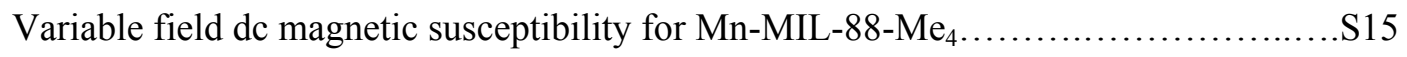

Alternate simulation to the de magnetic susceptibility for Mn-MIL-88-Me ${ }_{4} \ldots \ldots \ldots \ldots \ldots$.... 16

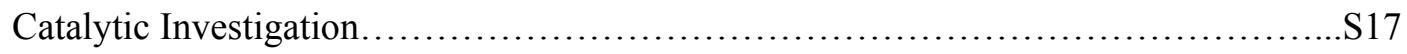

PXRD of Mn-MIL-88-Me $\mathrm{Me}_{4}$ for before and after catalysis........................... 18

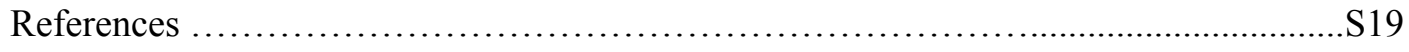


Chemicals and Materials: All chemicals and solvents were purchased from commercial suppliers and used without further purification. $\mathrm{Mn}\left(\mathrm{CH}_{3} \mathrm{COO}\right)_{2} \cdot 4 \mathrm{H}_{2} \mathrm{O}$, $\mathrm{Mn}\left(\mathrm{CH}_{3} \mathrm{COO}\right)_{3} \cdot 2 \mathrm{H}_{2} \mathrm{O}$, terephthalic acid $\left(\mathrm{H}_{2} \mathrm{BDC}\right)$, 2,3,5,6-tetramethylterephthalic acid $\left(\mathrm{H}_{2} \mathrm{BDC}-\mathrm{Me}_{4}\right)$, and acetic acid were purchased from Sigma-Aldrich. N, NDimethylformamide (DMF) (99.9\%) and acetone (99.8\%), were purchased from Fisher Chemical. Deionized water was used as the water source throughout the experiments.

Single-Crystal X-ray Structural Determination: The data of Mn-MIL-88 was collected at $100 \mathrm{~K}$ on a 'Bruker APEX-II CCD' diffractometer with a $\operatorname{MoK} \alpha(\lambda=0.71073 \AA)$ microfocus X-ray source. The single crystal was mounted on MicroMesh (MiTeGen) with paratone oil. The structures were determined by intrinsic phasing (SHELXT 2018/2) ${ }^{1}$ and refined by full-matrix least-squares refinement (SHELXL-2018/3) ${ }^{2}$ using the Olex2 ${ }^{3}$ software packages. The refinement results are summarized in Table S1. Crystallographic data for the Mn-MIL-88 structures in CIF format have been deposited in the Cambridge Crystallographic Data Centre(CCDC) under deposition numbers CCDC-1991790. The data can be obtained free of charge via www.ccdc.cam.ac.uk/data_request/cif (or from the Cambridge Crystallographic Data Centre, 12 Union Road, Cambridge CB2 1EZ, U.K.).

Powder X-ray diffraction analysis: PXRD data were collected at the IMSERC X-ray Facility at Northwestern University on a STOE-STADI-MP powder diffractometer equipped with an asymmetric curved Germanium monochromator $\left(\mathrm{CuK}_{\alpha 1}\right.$ radiation, $\lambda=$ $1.54056 \AA$ ) and one-dimensional silicon strip detector (MYTHEN2 1K from DECTRIS). The line focused $\mathrm{Cu}$ X-ray tube was operated at $40 \mathrm{kV}$ and $40 \mathrm{~mA}$. Powder was packed in a $3 \mathrm{~mm}$ metallic mask and sandwiched between two layers of polyimide tape. Intensity data from 2 to 30 degrees $2 \theta$ were collected over a period of 10-20 mins. The instrument was calibrated against a NIST Silicon standard (640d) prior the measurement.

Diffuse Reflectance Infrared Fourier Transform Spectroscopy (DRIFTS): DRIFTS spectra were recorded on a Nicolet 6700 FTIR spectrometer equipped with an MCT detector. The detector was cooled with liquid $\mathrm{N}_{2}$, and the spectra were collected under an Ar atmosphere. KBr was utilized as a background spectrum.

$\mathbf{N}_{2}$ Sorption studies: $\mathrm{N}_{2}$ isotherms were measured on Micromeritics Tristar II (Micromeritics, Norcross, GA) instrument at $77 \mathrm{~K}$. Pore-size distributions were obtained using DFT calculations using a carbon slit-pore model with a $\mathrm{N}_{2}$ kernel. MOF samples were activated at $90{ }^{\circ} \mathrm{C}$ under dynamic vacuum for $12-24 \mathrm{~h}$ on a SmartVac Prep from Micromeritics instrument. 
X-ray photoelectron spectroscopy (XPS): XPS measurements were carried out at the KECK-II/NUANCE facility at Northwestern University on a Thermo Scientific ESCALAB $250 \mathrm{Xi}(\mathrm{Al} \mathrm{K} \alpha$ radiation, $\mathrm{h} v=1486.6 \mathrm{eV}$ ) equipped with an electron flood gun. All spectra from XPS were analyzed as reference to the C 1s peak $(284.8 \mathrm{eV})$ by using Thermo Scientific Advantage Data System software

Magnetic Measurement. Direct-current (dc) magnetic susceptibility measurements were performed with a Quantum Design MPMS-XL SQUID magnetometer. The samples were activated prior to loading into polyethylene under an inert atmosphere as finely ground microcrystalline powders. Dc susceptibility measurements were performed at fields of 5000 and $10000 \mathrm{Oe}$, and the data were corrected for the diamagnetic contributions of the sample holder and the sample itself through the use of Pascal's constants. ${ }^{4}$ Magnetization curves ( $M$ vs. $H$ ) were recorded at $100 \mathrm{~K}$, from $0-4 \mathrm{~T}$ to check for the presence of unwanted ferromagnetic impurities. $\chi_{\mathrm{M}} T$ data were collected below 5000 Oe in the linear regime of $M$ vs. $H$.

The magnetic susceptibility data for both Mn-MIL-88 and Mn-MIL-88-Me 4 were simulated with the inclusion of isotropic $g$-values for both $\mathrm{Mn}$ (II) and $\mathrm{Mn}(\mathrm{III})$, axial zerofield splitting parameter $(D)$ and isotropic magnetic coupling parameters $J$ and $J^{\prime}$, where $\mathrm{J}=$ $J_{(\mathrm{Mn} 3+-\mathrm{Mn} 3+)}$, and $J^{\prime}=J_{(\mathrm{Mn} 3+-\mathrm{Mn} 2+)}$. To avoid over-parameterization of the simulation, isotropic $g$-values for $\mathrm{Mn}(\mathrm{II})$ were held at 2.0 , and its $D$-value constricted to 0 as well. This is warranted given the highly isotropic environment around six-coordinate $\mathrm{Mn}(\mathrm{II})$ ions. The $g$ values and $\mathrm{D}$-values for $\mathrm{Mn}$ (III) however were allowed to vary, constrained to values between $1.9<g_{\text {iso }}<2.0$, and $D$-values in the range of $-5 \mathrm{~cm}^{-1}<D<5 \mathrm{~cm}^{-1}$. These constrictions are in line with previously reported 6-coordinate $\mathrm{Mn}$ (II) and $\mathrm{Mn}$ (III) ions reported in the literature. It is worth noting the influence of $\mathrm{D}$ on the simulation of the data was minimal, as the curvature of the data is predominately determined by the $J$-values.

Best simulation of the magnetic susceptibility data suggested dramatic differences between Mn-MIL-88 and Mn-MIL-88-Me 4 . While both sets of data are expected to give rise to very similar, if not identical, magnetic properties, the contrast in the $J$ and $J^{\prime}$ parameters suggest different structures for $\mathrm{Mn}_{3} \mathrm{O}$ core in both frameworks. Mn-MIL-88 suggests the $\mathrm{Mn}_{3} \mathrm{O}$ core observed crystallographically is preserved, with antiferromagnetic coupling between all three Mn sites, with values comparable to those previously reported in the literature. In contrast, the magnetic coupling parameters in Mn-MIL-88-Me 4 , for which no single crystal structure could be obtained suggests there is very weak, and negligible coupling between the $\mathrm{Mn}(\mathrm{II})$ ion and the Mn(III) ions. This in turn suggests breaking of the $\mathrm{Mn}(\mathrm{II})$-oxo bond that eliminates the orbital pathway for antiferromagnetic exchange. An alternate simulation of the data, in which both $J$ and $J^{\prime}$ are restrained in the range of -4 to - 
$15 \mathrm{~cm}^{-1}$ (values comparable to those observed in Mn-MIL-88) resulted in a poor simulation (see Figure S9). An alternate explanation for the divergences in the magnetic behavior could be the result of anti-exchange interactions that produce a less pronounced decrease in $\chi_{\mathrm{M}} T$ as the temperature decreases. Antisymmetric exchange interactions are prominent in frustrated systems such as those presented herein, however the inclusion of these parameters is unwarranted without further evidence to their presence. Additionally, the strange kink present in the $\chi_{\mathrm{M}} T$ data for Mn-MIL- 88 is difficult to reproduce in the simulation. We believe it is likely the result of the collapsed framework that may lead to additional coupling interactions between adjacent $\mathrm{Mn}_{3} \mathrm{O}$ units. 


\section{Crystallographic data of Mn-MIL-88}

\section{Table S1 Crystal data and structure refinement for Mn-MIL-88.}

Empirical formula

Formula weight

Temperature/K

Crystal system

Space group

$\mathrm{a} / \AA ̊$

$\mathrm{b} / \AA$

$\mathrm{c} / \AA \AA$

$\alpha /^{\circ}$

$\beta /{ }^{\circ}$

$\gamma /{ }^{\circ}$

Volume $/ \AA^{3}$

Z

$\rho_{\text {calc }} \mathrm{g} / \mathrm{cm}^{3}$

$\mu / \mathrm{mm}^{-1}$

$\mathrm{F}(000)$

Crystal size $/ \mathrm{mm}^{3}$

Radiation

$2 \Theta$ range for data collection/ ${ }^{\circ}$

Index ranges

Reflections collected

Independent reflections

Data/restraints/parameters

Goodness-of-fit on $\mathrm{F}^{2}$

Final R indexes [I $>=2 \sigma(\mathrm{I})]$

Final $\mathrm{R}$ indexes [all data]

Largest diff. peak/hole / e $\AA^{-3}$
$\mathrm{C}_{8} \mathrm{H}_{4} \mathrm{MnO}_{5.33}$

240.39

100.15

orthorhombic

Cmcm

16.0846(16)

25.266(3)

16.7653(19)

90

90

90

6813.3(13)

12

0.7030

0.579

1441.1

$0.2 \times 0.1 \times 0.1$

Mo K $\alpha(\lambda=0.71073)$

3 to 48.14

$-17 \leq \mathrm{h} \leq 18,-19 \leq \mathrm{k} \leq 28,-19 \leq 1 \leq 19$

9198

$2901\left[\mathrm{R}_{\mathrm{int}}=0.0470, \mathrm{R}_{\text {sigma }}=0.0483\right]$

2901/0/112

1.025

$\mathrm{R}_{1}=0.0700, \mathrm{wR}_{2}=0.2025$

$\mathrm{R}_{1}=0.0796, \mathrm{wR}_{2}=0.2158$

$2.07 /-1.16$ 
Thermogravimetric analysis of Mn-MIL-88 and Mn-MIL-88-Me 4

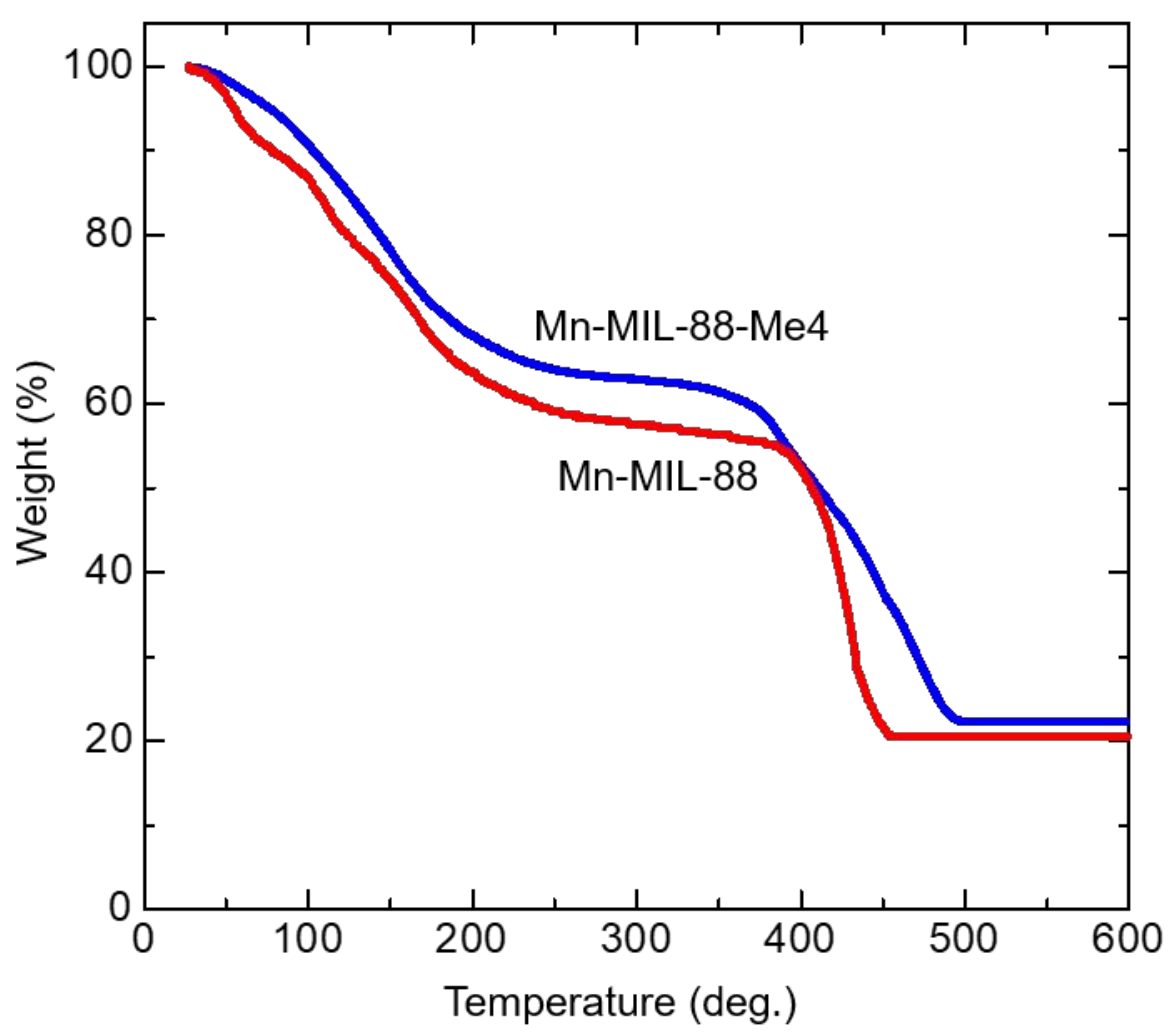

Figure S1 TGA profile of Mn-MIL-88 (red) and Mn-MIL-88-Me 4 (blue) under $\mathrm{N}_{2}$ condition with a 10 degree/min rate. 
Pore size distribution of Mn-MIL-88-Me

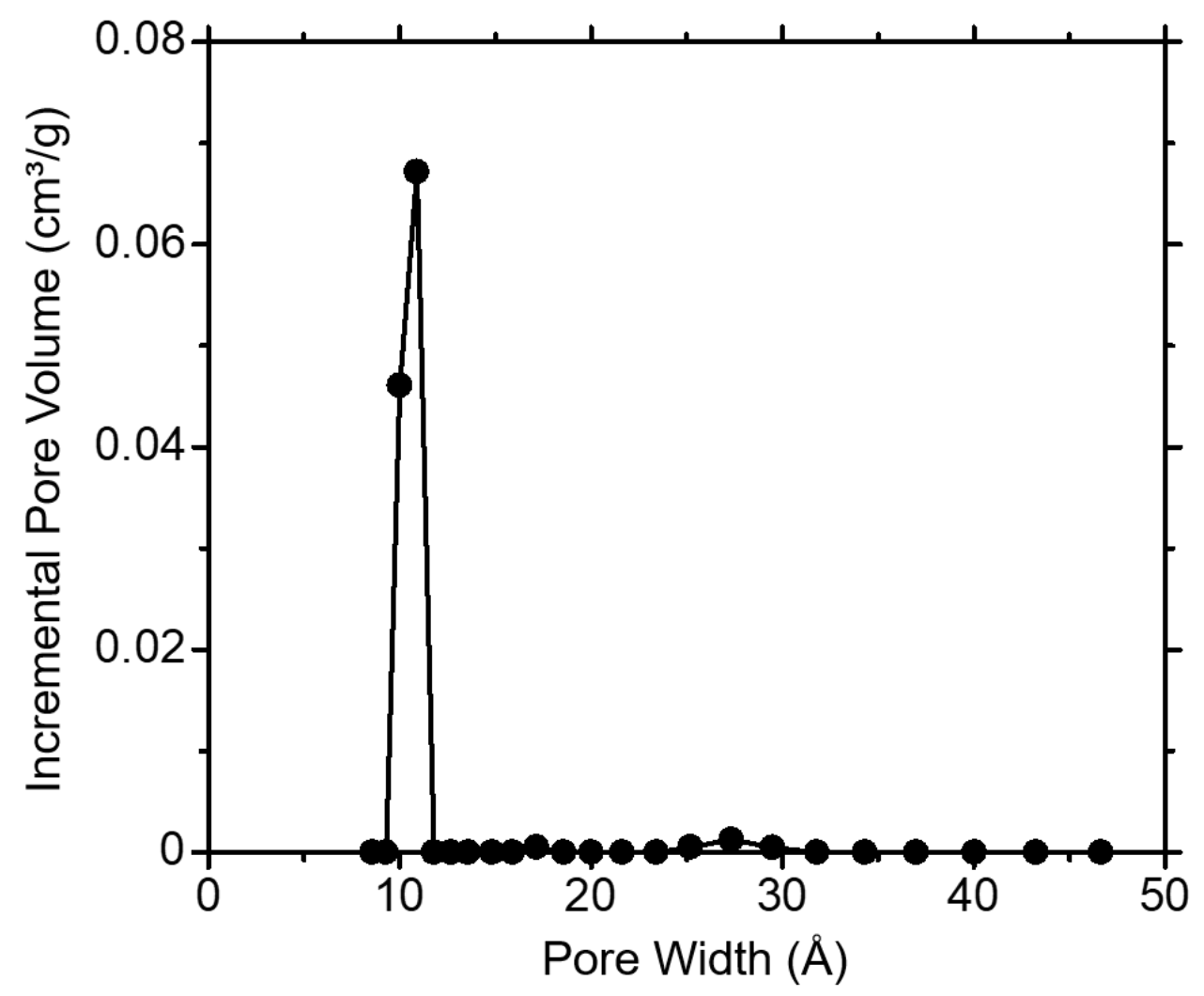

Figure S2 Pore size distribution for Mn-MIL-88-Me 4 
${ }^{1} \mathrm{H}$ NMR spectra of Mn-MIL-88 and Mn-MIL-88-Me
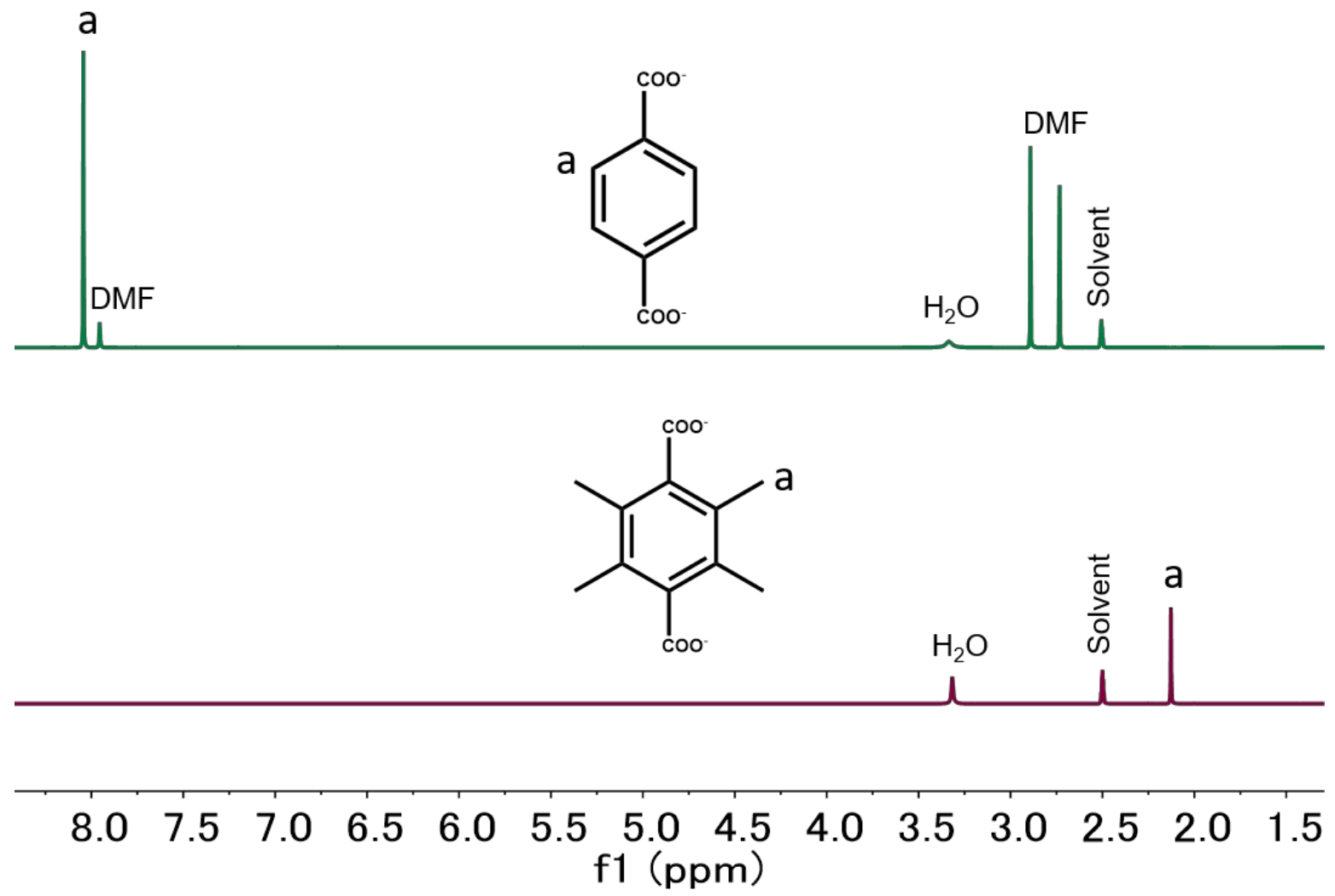

Figure S3. ${ }^{1} \mathrm{H}$ NMR spectra of Mn-MIL-88 (top) and Mn-MIL-88-Me 4 (bottom). $\left(\mathrm{NaOD} / \mathrm{d}_{6}-\mathrm{DMSO}, 500 \mathrm{MHz}\right)$ 
IR spectra for Mn-MIL-88 and Mn-MIL-88-Me

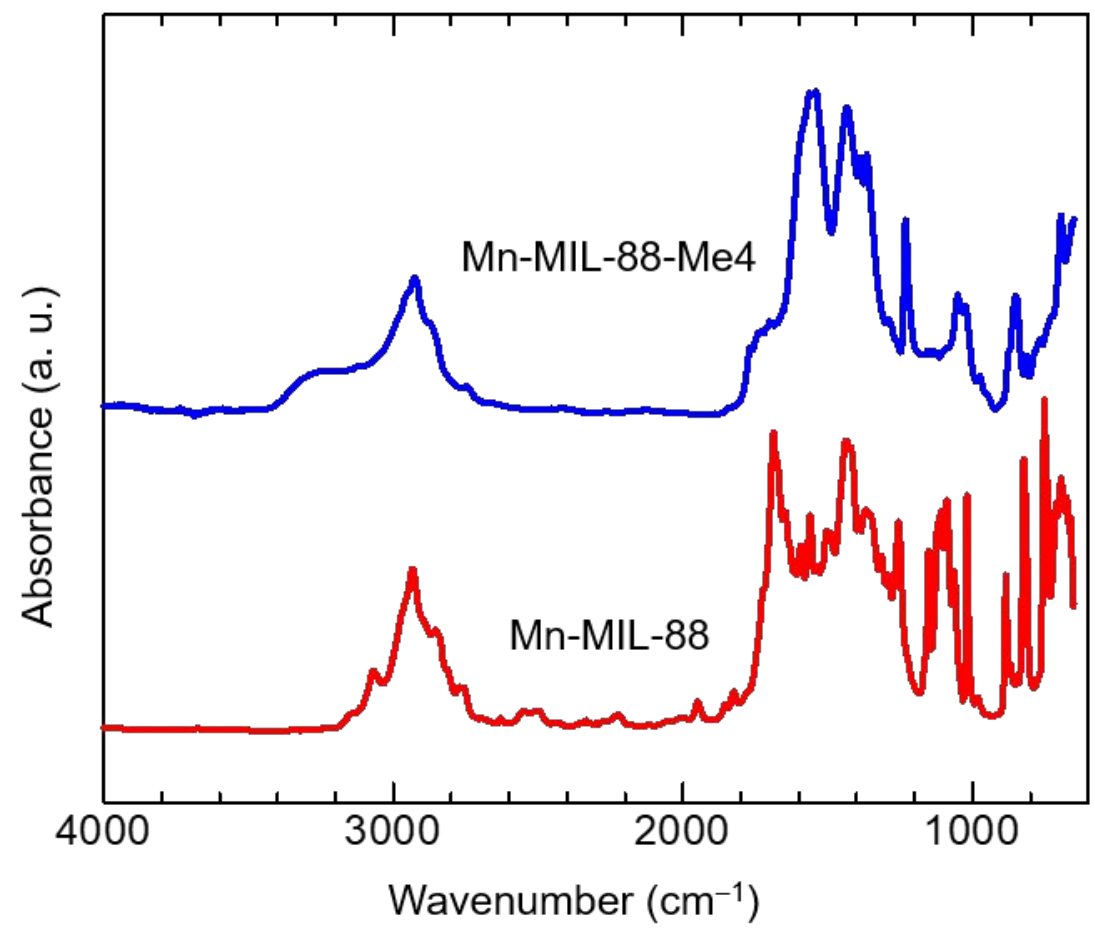

Figure S4 IR spectra of Mn-MIL-88 (red) and Mn-MIL-88-Me4 (blue) 
XPS for Mn-MIL-88, Mn-MIL-88-Me 4 , Mn(II) salt and Mn(III) salt

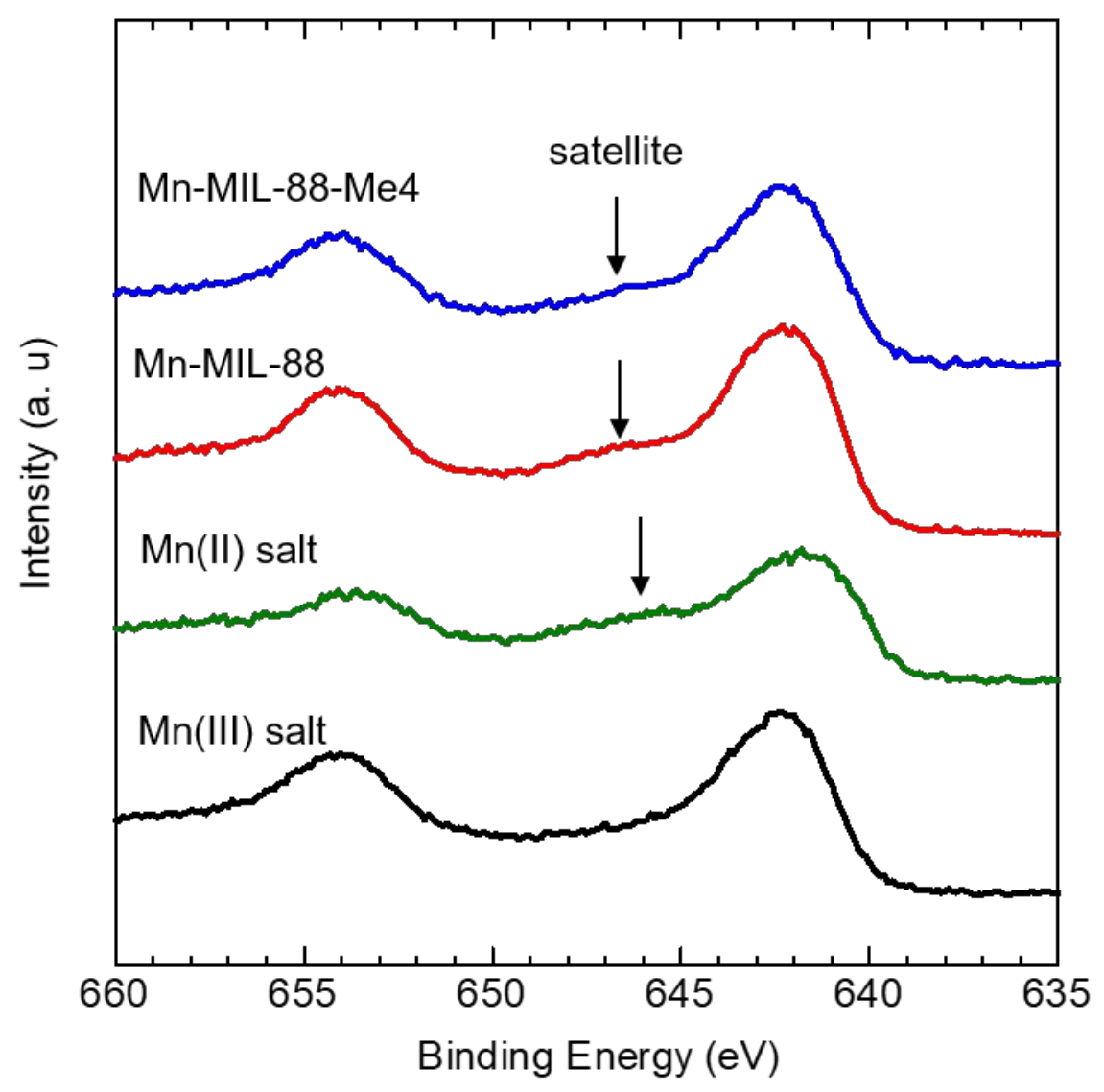

Figure S5 The comparison of $\mathrm{Mn} 2 \mathrm{p}$ core-level spectra between $\mathrm{Mn}(\mathrm{III})$ salt $\left(\mathrm{Mn}\left(\mathrm{CH}_{3} \mathrm{COO}\right)_{3} \cdot 2 \mathrm{H}_{2} \mathrm{O}\right)$ (black), $\mathrm{Mn}(\mathrm{II})$ salt $\left(\mathrm{Mn}\left(\mathrm{CH}_{3} \mathrm{COO}\right)_{2} \cdot 4 \mathrm{H}_{2} \mathrm{O}\right)$ (green), Mn-MIL-88 (red) and Mn-MIL-88-Me ${ }_{4}$ (blue). Satellite peak observed in $\mathrm{Mn}(\mathrm{II})$ since absence in $\mathrm{Mn}(\mathrm{III})$. 

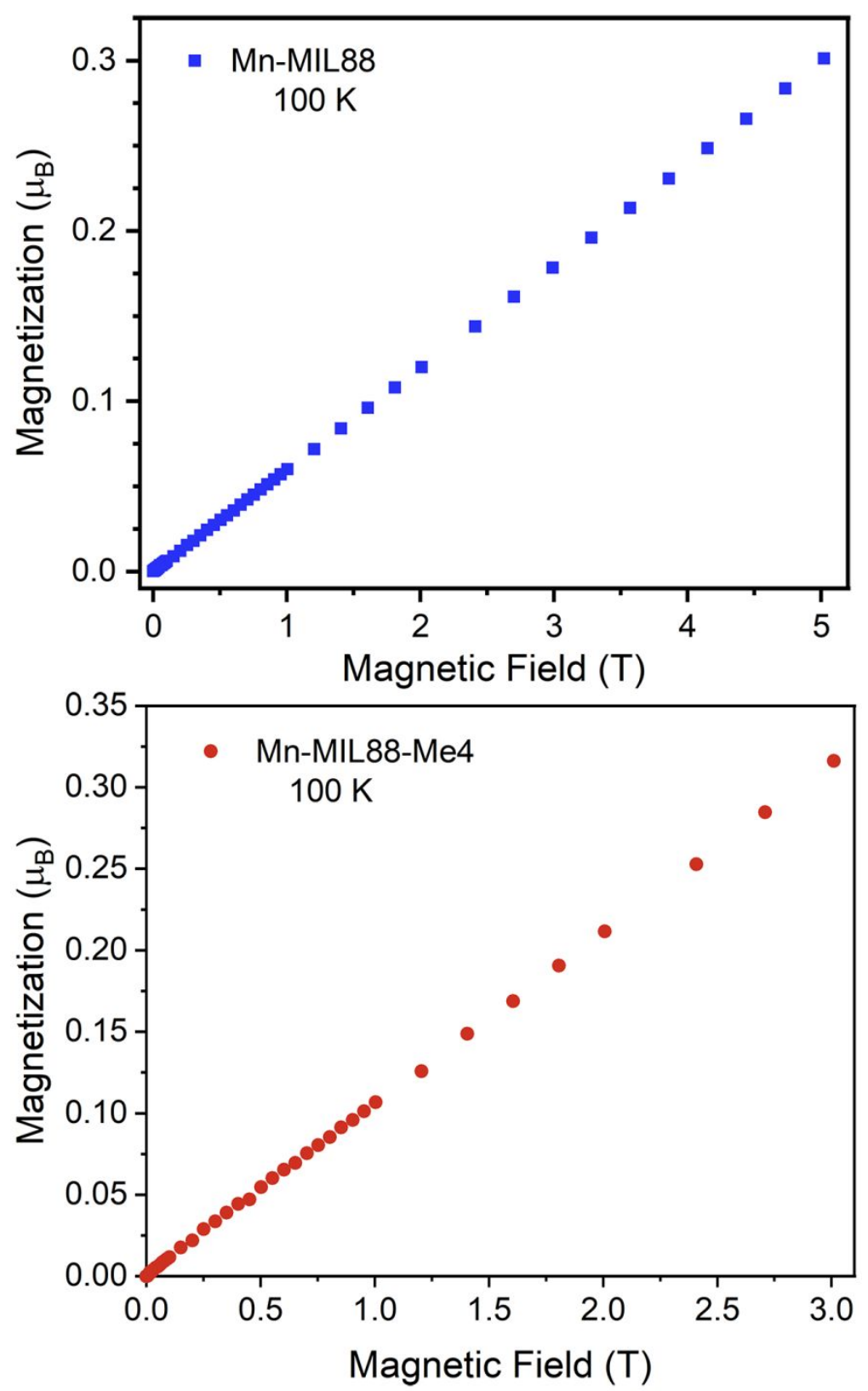

Figure S6 Variable magnetic field magnetization data collected at $100 \mathrm{~K}$ for Mn-MIL-88 (top) and Mn-MIL-88-Me 4 (bottom). The lack of curvature at low magnetic fields indicates the lack of ferromagnetic impurities. 


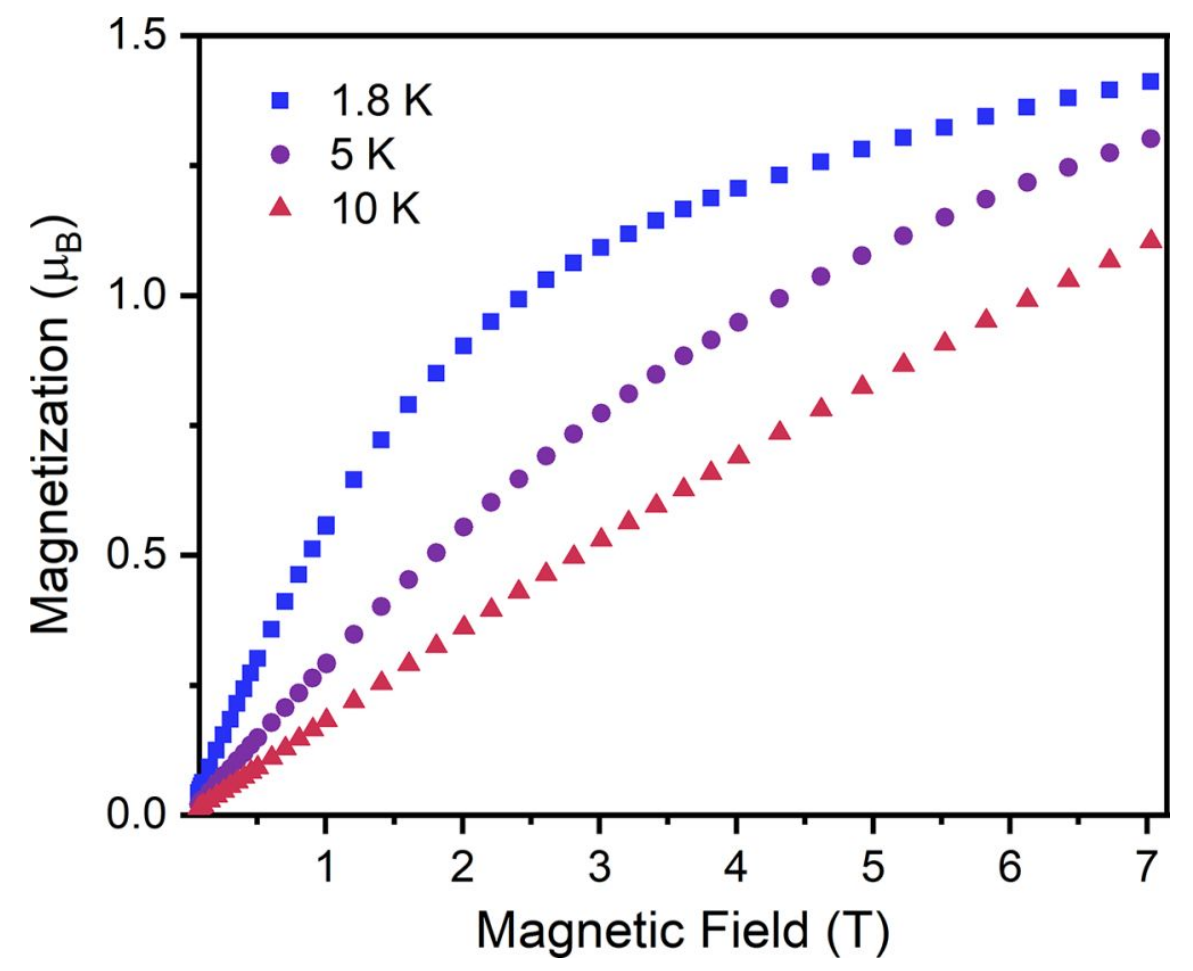

Figure S7 Variable temperature magnetization data collected at 2, 5, and $10 \mathrm{~K}$ for Mn-MIL88. The saturation magnetization value at $1.8 \mathrm{~K}$ supports a ground state spin of $1 / 2$ with lowlying, thermally accessible spin states. 


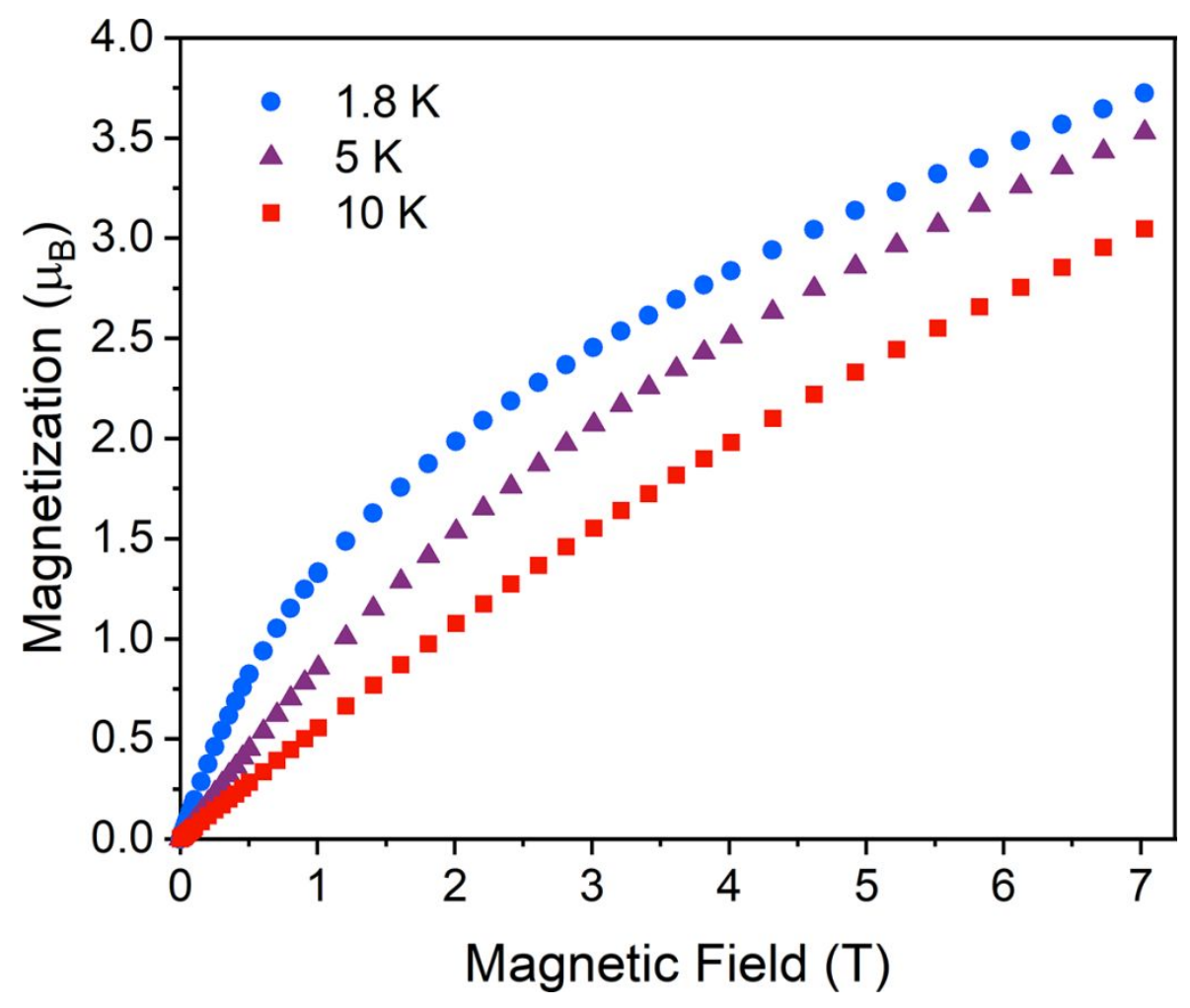

Figure S8 Variable temperature magnetization data collected at 2, 5, and $10 \mathrm{~K}$ for Mn-MIL$88-\mathrm{Me}_{4}$. The saturation magnetization value at $1.8 \mathrm{~K}$ supports a ground state spin of $3 / 2$ with low-lying, thermally accessible spin states. 


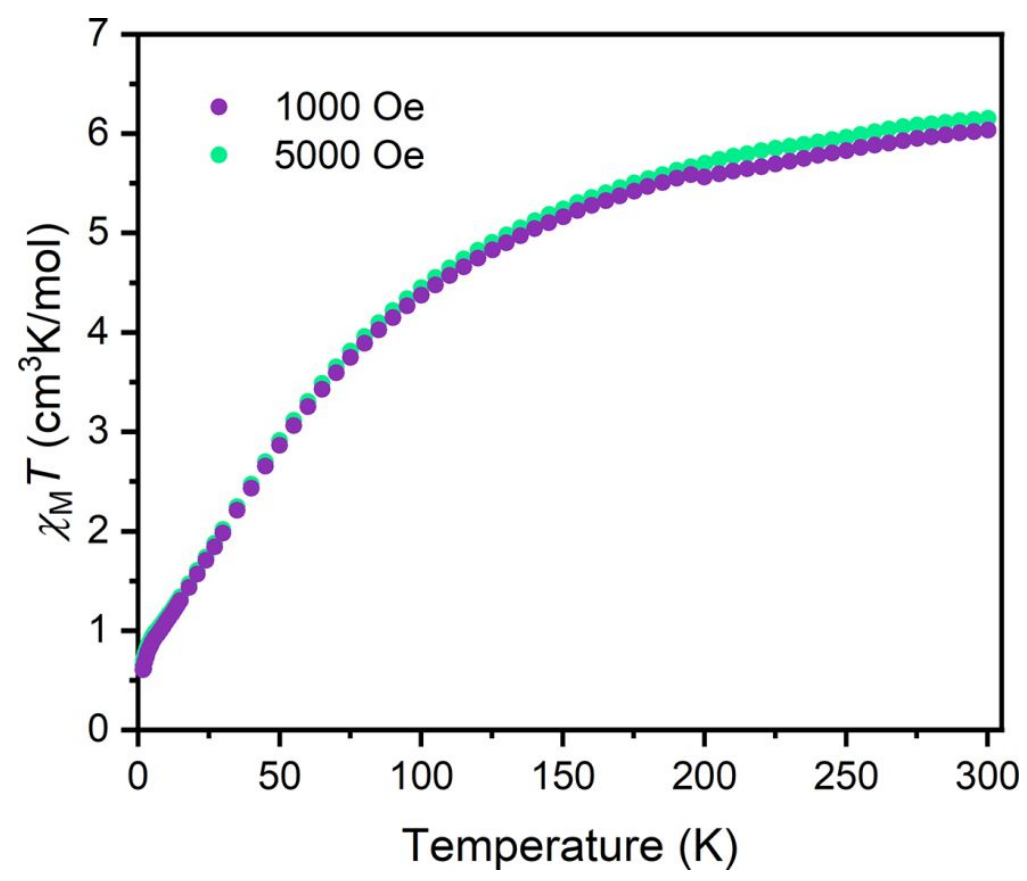

Figure S9 Dc magnetic susceptibility of Mn-MIL-88. Data was collected in the temperature range of $1.8-300 \mathrm{~K}$, at magnetic fields of $1000 \mathrm{Oe}$ and $5000 \mathrm{Oe}$. The near perfect overlay of the variable field data precludes the presence of any paramagnetic impurities within the sample. The abrupt change at $175 \mathrm{~K}$ in the 1000 Oe data is the result of the sample shifting during the measurement. The lack of further divergence between the data at different with increasing temperature supports the absence of paramagnetic impurities in the sample. 


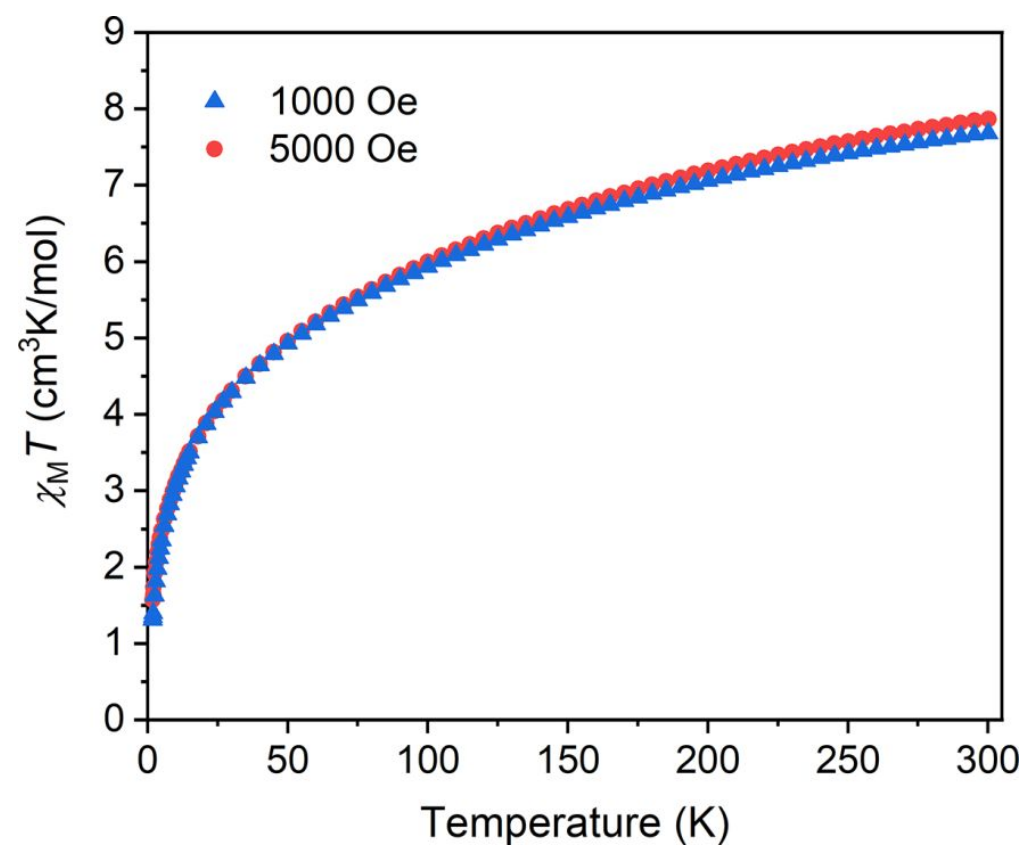

Figure S10 De magnetic susceptibility of Mn-MIL-88-Me 4 . Data was collected in the temperature range of $1.8-300 \mathrm{~K}$, at magnetic fields of $1000 \mathrm{Oe}$ and 5000 Oe. The divergence of the data between the two magnetic fields indicates the presence of a small paramagnetic impurity, likely attributed to high-spin Mn(III) ions within the sample. 


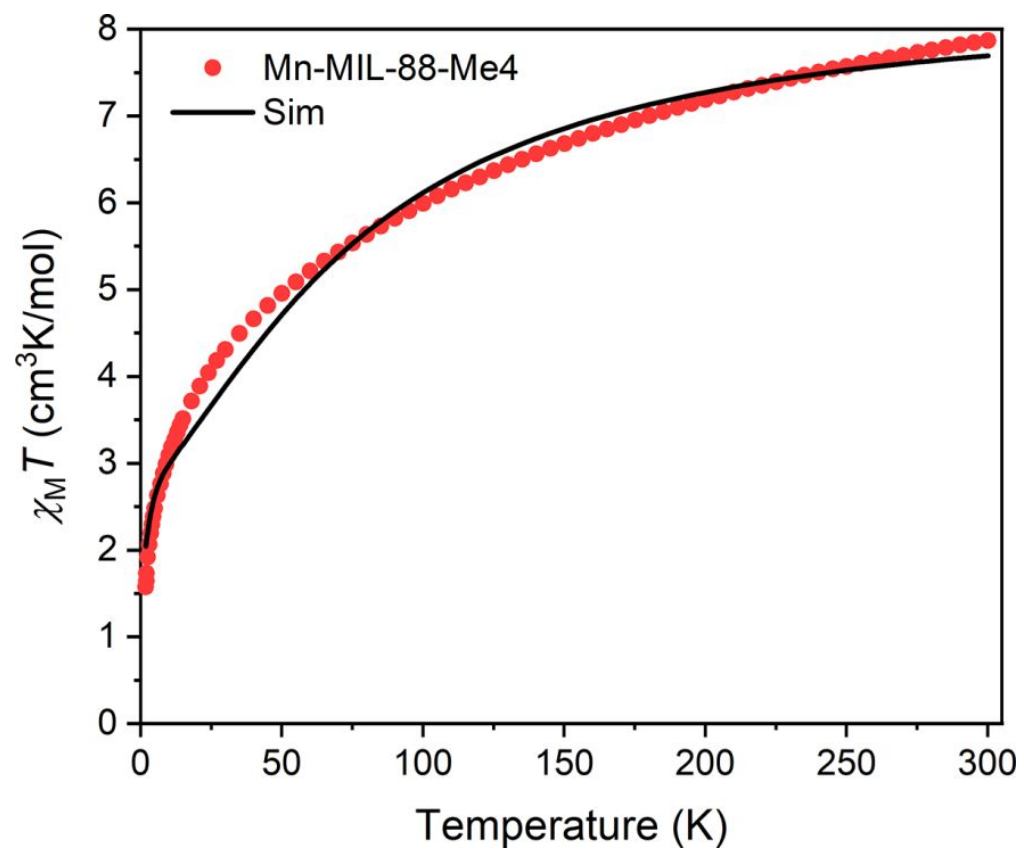

Figure S11 Dc magnetic susceptibility of Mn-MIL-88-Me 4 . Data was collected in the temperature range of $1.8-300 \mathrm{~K}$, at magnetic fields of $5000 \mathrm{Oe}$. The simulation to the data afforded alternate fitting parameters than those presented in the main manuscript. $\mathrm{J}$ and $\mathrm{J}$ ' were constrained in this fit to be non-zero. The simulation afforded values of $-6.14 \mathrm{~cm}^{-1}$ and $-2.4 \mathrm{~cm}^{-1}$, respectively. The values of $g$ and $D$ remained unchanged relative to those presented in the main text. 


\section{Catalytic Investigation}

\section{Experimental procedures}

The MOF catalysts were heated at $100{ }^{\circ} \mathrm{C}$ for ca. $1 \mathrm{~h}$ prior to the reactions. To a $10 \mathrm{~mL}$ Biotage microwave vial, 4-methoxybenzyl alcohol $(1 ; 76 \mu \mathrm{L}, 0.61 \mathrm{mmol})$, triethylamine (7 $\mu \mathrm{L}, 0.61 \mathrm{mmol})$, mesitylene (internal standard: $30 \mu \mathrm{L}, 0.21 \mathrm{mmol}), \mathrm{Mn}-\mathrm{MIL}-88-\mathrm{Me}_{4}(8$ mol\%, $41 \mathrm{mg})$, and toluene $(1 \mathrm{~mL})$ were added and sealed. The system was purged with $\mathrm{O}_{2}$ for $1 \mathrm{~h}$ and connected to an oxygen balloon, and then the vials were heated at $105^{\circ} \mathrm{C}$ under mechanical stirring. At 1-6 h intervals after heating, $\sim 0.05 \mathrm{~mL}$ of the reaction mixture was removed from the system using a $1 \mathrm{~mL}$ syringe. The aliquots were diluted with $1 \mathrm{~mL}$ of acetone, and insoluble solids were removed by centrifuge. The product yield was determined by internal standards.

Control reaction without catalyst.

Same reaction was carried out without Mn-MIL-88-Me ${ }_{4}$ at $105{ }^{\circ} \mathrm{C}$ for $50 \mathrm{~h}$. At $1-6 \mathrm{~h}$ intervals after heating, $\sim 0.05 \mathrm{~mL}$ of the reaction mixture was removed from the system using a $1 \mathrm{~mL}$ syringe and diluted with $1 \mathrm{~mL}$ acetone. The product yield was determined by internal standards. 
PXRD of Mn-MIL-88-Me ${ }_{4}$ for before and after catalysis

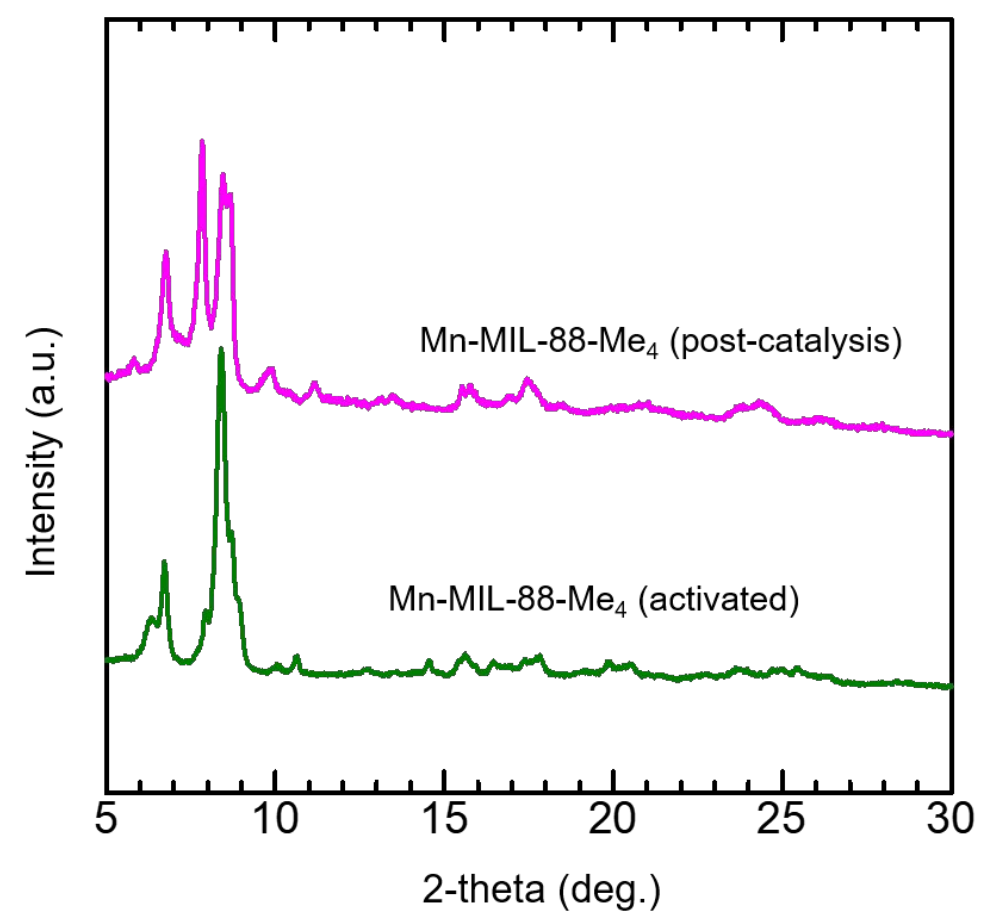

Figure S12 PXDR pattern of Mn-MIL-88- $\mathrm{Me}_{4}$ before (activated) and after catalysis (post catalysis). 


\section{References}

(1) Sheldrick, G. Acta Crystallogr A 2015, 71, 3-8.

(2) Sheldrick, G. Acta Crystallographica Section C 2015, 71, 3-8.

(3) Dolomanov, O. V.; Bourhis, L. J.; Gildea, R. J.; Howard, J. A. K.; Puschmann, H. J. Appl. Crystallogr. 2009, 42, 339-341.

(4) Bain, G. A.; Berry, J. F. Diamagnetic Corrections and Pascal's Constants. J. Chem. Ed. $2008,85,532$. 